\title{
Balancing exercises: Subjectivised narratives of balance in cancer self-health
}

\section{John I MacArtney}

University of Oxford, UK

\begin{abstract}
Having a 'balanced lifestyle' is often promoted as one way to manage the competing demands of contemporary life. For people with cancer, those demands are often multiplied, particularly when they use self-health approaches that seek to bring together an array of biomedical and complementary and alternative medicine therapies and practices. Yet, how balance is used in this complex healthcare milieu and the affects it has on experiences of illness are less well understood. In order to follow the polyphonic narratives involved, two case studies of women with breast cancer who used cancer self-health approaches were analysed. By exploring different modes of subjectivation in the case studies, balance was found to affect experiences of health in contemporary society in multiple ways. In particular, it was one way through which participants saw themselves as being able to maintain a critical engagement not just with their healthcare, but with their self and life.
\end{abstract}

\section{Keywords}

cancer and palliative care, complementary and alternative medicine, experience of illness, narrative analysis

\section{Introduction}

People are regularly urged to find a better balance in all areas of their lives, including work, diet, mental health, time-management and exercise (Shapin, 2011). It is an idea that exists in both Western culture, such as striving to have a work-life balance (Wagman et al., 2011), as well as Eastern traditions, such as traditional Chinese medicine's yin and yang or the balance of the tridosha in Ayurveda (Patwardhan et al., 2005). Techniques

\section{Corresponding author:}

John I MacArtney, Health Experiences Research Group, Nuffield Department of Primary Care Health Sciences, Radcliffe Observatory Quarter, University of Oxford, Oxford OX2 6GG, UK.

Email: john.macartney@phc.ox.ac.uk 
and practices about how to be better balanced are now promoted in a range of industries, from self-help movements to occupational health professions to corporate food giants, so much so that there has been a normalisation of balance as an idealised practice (Christiansen and Matuska, 2006; Shapin, 2011). Hence, when people with serious illnesses, such as cancer, look beyond biomedicine for help, it is unsurprising to find that they often describe a need to take a more balanced approach to both treating their illness and to their lives generally (e.g. Lipworth et al., 2011; Mullen, 1992; Nissen, 2013; Sointu, 2006a).

The experiences of those with cancer have been a fertile ground for analysis and reflection of contemporary healthcare norms, values and practices (e.g. Broom, 2009; Frank, 1995; Lawton, 1998), as have analysis of those people with cancer who use complementary and alternative medicine (CAM) (MacArtney, 2014; Bell, 2010; Broom and Tovey, 2007; Gale, 2011; Sointu, 2013; Stacey, 1997). This CAM use might include any of a heterogeneous range of practices, treatments and therapies including the psychological, nutritional, body-work, psychic and spiritual, as well as 'alternative' healing systems (Bendelow, 2009) that, in turn, can be grouped into 'whole system' approaches like homeopathy or less ideological practices like reiki (Broom and Tovey, 2007: 1024). With up to 40 per cent of people with cancer choosing to include some form of CAM in their healthcare (Horneber et al., 2012), this popular use of CAM has not gone unnoticed with many CAM modalities being critiqued for their claims to efficacy (e.g. Goldacre, 2008; Singh and Ernst, 2009). However, as pertinent as these commentaries are, it is the historical, social and cultural factors that have provided insights into peoples' ongoing use of CAM (MacArtney, 2014; Bivins, 2007; Gale, 2014; Saks, 2003; Sointu, 2012; Wahlberg, 2007).

CAM use is better understood not through simplistic binaries (Gale, 2014), such as CAM being the Other to biomedicine (Saks, 2003), but as part of a 'big picture' approach to healthcare (Gale, 2014: 810). Explorations of how CAM might be able to work alongside biomedical care have previously focused on developing 'integrated' systems in a pluralistic healthcare field (Cant and Sharma, 1998; Coulter, 2004). Yet, these attempts frequently pointed to the limitations of integration, as hierarchies and differences between biomedicine and other healthcare approaches were reinforced rather than broken down (Gale, 2014; Wahlberg, 2007). However, CAM use today can also be understood as part of a wider 'self-health' (Stacey, 1997) trend that sees users bringing a range of healthcare modalities together as part of a bricoleur approach to healthcare (Broom, 2009). These hybrid approaches to the healthcare field not only bring more possibilities but also more complexity as it now falls to users to respond to contemporary norms to care for their self and health (MacArtney, 2015; Frank, 1998; Gale, 2014; Novas and Rose, 2000; Rose, 2007).

In response, ideas, practices and techniques of 'balance' are one way people can negotiate this seemingly increasingly complex milieu of healthcare; as one cancer self-health programme advocated to its users, 'the emphasis is on seeking to achieve equilibrium, the right balance for you' (Beales, 2003: 39). While an ontology of balance has been developed (Christiansen and Matuska, 2006; Lipworth et al., 2011; Wagman et al., 2011), this article aims to explore an area that has received less attention: how ideas, practices and techniques of balance affect peoples' experiences of cancer, particularly when they are engaged with modalities of self-health (MacArtney, 2015; Broom, 2009). 


\section{Modalities of balance}

Ideas of balance have a history of being used to position CAM as offering users something either from outside of biomedicine or that biomedicine had neglected (Saks, 2003). Hence, the idea that CAM offers something to balance out what is lacking extends beyond concerns with the sick body, to finding ways to better manage personal and professional obligations (Flesch, 2010), and address concerns about wellbeing (Sointu, 2006a). Balance is therefore often understood as a practice through which numerous oppositions found in healthcare - such as between the mind and body, hope and fate, empowerment and disenfranchisement - are negotiated (Daykin et al., 2007; Wagman et al., 2011). As a space where multiple dimensions of healthcare and wellbeing coincide, cancer self-health approaches portend to be an important site of analysis of how balance affects experiences and understandings of the self, health and life (MacArtney, 2015; Broom and Tovey, 2007; Mullen, 1992; Shapin, 2011).

A number of studies have highlighted the significance of balance in contemporary healthcare and have provided the ontological contours of the concept (Christiansen and Matuska, 2006; Mullen, 1992; Shapin, 2011). In particular, Lipworth et al. (2011) conducted an instructive conceptual meta-analysis of the use of balance in qualitative studies of healthcare to provide a typology of balance. Lipworth et al. divided balance into four analytical typologies, including two mechanisms of balance (as a state or as a process) and two orientations (internalist and externalist). Balance as a state was recognisable as an object or thing (e.g. the person's mind or body) that might be optimised and as such hold a moment of permanence, no matter how fleeting. In contrast, when balance was a process, the focus was on activities that sought to manage, integrate or hedge the risks and rewards of multiple commitments. This entailed considerable effort, as there was rarely any sense that a state of balance could be achieved for long. Indeed, what linked both mechanisms (state and process) was the experience of balance as fragile, unstable or temporary. Furthermore, while externalist balancers gave little attention to defining what balance was - either as a state or process - Lipworth et al. (2011) found the other end of the spectrum were the 'internalist balancers' (p. 720) who saw balance as part of a personal life project. Here, individualised practices were utilised in a self-reflective and empowered structuring of their lives:

The internalist balancer did not exist in a social vacuum, but had a very different way of relating to others. Unlike the externalist balancer, who had a community orientation, the internalist balancer focused on enacting his or her autonomy. Indeed, people could use balancing to actively resist social expectations. (Lipworth et al., 2011: 720)

Lipworth et al. (2011) also hypothesised that there might be a link between the orientation of the internalist balancer and the mechanisms of balance as a process. However, they recognised that while their typology provided a more detailed demarcation of the ways that balance can be conceptualised, they were unable to consider the relationship between 'grand narratives' (p. 722) of balance and individual's use of balance in their self-care. This article aims, in part, to bridge this gap by focusing on the everyday understandings and usages of balance by two women with cancer. Most importantly, it will 
elucidate the 'shifting' adaptation of perspectives of balance as these women form their criticality as 'complex, multi-dimensional bodies' (Meurk et al., 2013: 314).

\section{Problems of subjectivation}

Although inculcations of balance have been under-considered, practices of subjectivation have been given much more attention. Using Foucault's work as a theoretical starting point, ${ }^{1}$ cancer self-health, as a form of hybrid or bricoleur healthcare (Broom, 2009), shares 'cultural synergies with neoliberal governance of health' (Fries, 2008: 358). For example, the potentially emancipating role of self-help in self-health might also be conceived as a technology of the individually responsible self, which brings the user back within neoliberal practices for governing health behaviours (Illouz, 2008; Youll and Meekosha, 2011). Similarly, CAM use by women that was posited as an escape from gender norms found in biomedicine has been found to reinforce many gendered aspects of healthcare (Nissen, 2013; Sointu, 2006b; Stacey, 1997). However, others have argued that while using CAM and self-help might result in reconfigured disciplinary practices and techniques of governance, it is also possible to demonstrate that within these discourses, practices and technologies of the self is the potential for the user to refashion her self beyond such boundaries (MacArtney, 2015; Broom, 2009; Fullagar, 2002; Meurk et al., 2013; Sointu, 2013).

This is to argue that within Foucault's work, there is the possibility of a more nuanced position than simply positing that following health advice is subjugation and rejecting it is resistance (Armstrong and Murphy, 2012). Of particular interest are Foucault's (2005) explorations of how the self comes to understand its self in its subjectivity. A crucial distinction that helps to elucidate what is at stake here is that between subjugation and subjectivation. Foucault often used assujettissement, which translates to submitting to, subjection or subjugation, in contrast to subjectivation, through which individuals are guided in their own process of becoming capable of governing themselves and others (Harrer, 2005: 79). Following McGushin (2007), it is therefore helpful to interpret Foucault's later work as part of a project to explore the 'exercises' (askēsis) of subjectivation, to demonstrate the ambiguities of incorporation and limitations of interpellation. The interest therefore is in identifying the active and ongoing work done by the user of cancer self-health to critically situate the forming of her self as an object or subject within her subjectivity.

One example of this approach can be found in Foucault's (1998) consideration of the ancient Greeks' attempts to avoid the excesses of pleasure and consequently avoid becoming enslaved to them. It is possible to say that the practices of self-mastery were, then, attempts to gain freedom via a life of moderation (McGushin, 2007), a form of subjectivising balance. Crucially, in order to locate the ethical and disciplinary content in these practices of subjectification, Foucault explored both the corporeality of these ancient accounts as well as the telos to which these were put. In turn, this analysis engages the embodied lived experiences of using cancer self-health as well as the narrated trajectories of those experiences. This is because within peoples' narrations of their emotional reasoning are their evaluative and normative judgments about their self, health and life (Sayer, 2011). So while the disciplinary and ethical practices within subjectivation may be 
ambivalent (Frank, 1998), by exploring the ways those using cancer self-health inculcate, affect and transform their experiences of healthcare (their exercises of subjectivation) and the narrative trajectories in which this takes place (telos), we can consider how balance might be morally understood (Broom, 2009; Frank, 1998; McGushin, 2007; Sayer, 2011).

\section{Methods}

The analysis explores the case studies of 'Fiona' and 'Karen' who had breast cancer and who used cancer self-health approaches as part of their healthcare. The interviewees were recruited from two cancer self-health centres in the south of England. Ethical approval for the study was provided by the PhD ethics committee of the author's institution, while the directors of the cancer centres provided site-specific ethical approval and granted access after meetings to discuss the scope of the study. The aim of the main study was to explore conceptualisations of subjectivity in the stories of people who have, or have had, cancer and who used complementary therapies and self-help. Potential interviewees were those who currently or previously had cancer and who had self-identified as using CAM.

An opportunity sample was used as interviewees were recruited passively via posters and leaflets left at the Centres, which directed them to the research website (no longer active). Sixteen interviews took place between 2009 and 2011, of which two interviewees were male. Six interviewees, including Fiona and Karen, were receiving ongoing treatment at the time of the interview. Consent was provided before the interview started and all the interviews were digitally recorded and fully transcribed. The interviews took place either at the interviewee's home, as they did for Fiona and Karen, or at the Centre, whichever was preferred by the interviewee. The interviews were largely unstructured and started with the interviewer asking the interviewee to 'tell me your story', which allowed the individual participant to determine the information that is relevant to the discussion (Overcash, 2003). The interviews lasted between 45 minutes to 1.5 hours.

Case-study designs have a significant precedence in healthcare research (e.g. Farmer, 1996; Lawton, 1998; Lorenz, 2011; Sparkes et al., 2012). This is because case studies are suited to analysis that draws on multiple and complex data sources (Yin, 2003), such as the in-depth interviews and the cancer self-health materials used by the interviewees. Case-study designs also allow for an in-depth analysis of narratives and allow for a consideration of how themes emerge and interplay within a case (Riessman, 2003) and so provide useful 'exemplars' that help develop interpretation of a field (Flyvbjerg, 2006: 242). Therefore, of the interviews completed, the two cases were selected not because they were 'typical' stories, but because their stories provided 'vivid' accounts of balance (Frank, 2010: 75). In particular, it might be assumed that Fiona's and Karen's narratives, as a psychotherapist and a practitioner of Alexander Technique, respectively, had greater exposure to cancer self-health narratives. That is, the strategy of focusing on two cases provided an in-depth analysis that located experiences of balance within the polyphonic narratives of illness and life more generally (Frank, 2010).

The process of analysis started during data collection and transcription. Initially, the aim was to identify different forms and modalities of balance within the interviewee's story. Following this, the connections of balance narratives in relation to other narratives 
in the interviewee's story were explored. By juxtaposing the multitude of narratives within the interviewee's story, it was possible to provide an analytical exploration of how narratives of balance were used by an interviewee in the formation of her self in her illness story. The process itself entailed reading and re-reading the interview transcripts to find examples, continuities and contradictions that would help build-up an analysis of the interview (Frank, 2010). The results below attempt to provide an 'honest' (Back, 2007: 19) description of how the raw interview data connect to abstract and theoretical concerns of the article.

The later stages of the analysis entailed returning to the cancer self-health materials the interviewees had referenced during their interviews, such as books, websites, magazines and survivor memoires. This enabled an exploration of how the interviewees folded-in and re-situated the practices and guidance that such materials gave. Finally, the sociological and theoretical literatures were considered to explore possible conceptual tools that could help make sense of the findings.

\section{Findings}

\section{Fiona - balancing effects: moving between ideology and realism}

Fiona's story was one of multiple experimentations as she sought alternative treatments to attain the goal of physical reduction of her tumour. Despite the appearances of being radically alternative, with the accounts infused with counter-biomedical suspicion, Fiona's experience was 'grounded' (as she said) in detecting physical results and change. This bodily materialism balanced out her therapeutic and ideological experimentation in an ongoing process that brought her, reluctantly but pragmatically, to have chemotherapy.

Fiona was diagnosed with breast cancer in her right breast in July 2008. She described how she had not perceived herself to be in a high-risk category, having not smoked or taken drugs and with no familial history of breast cancer. Fiona, now in her early $30 \mathrm{~s}$, also said that since she was 21 , she had an active interest in alternative lifestyles - a narrative of exploration that continued as she sought treatment for cancer. Fiona talked about the amount of time she initially spent on the Internet researching treatments, but over time, she utilised two forms of cancer self-health for information and advice: one was an information and advice resource helpline and website, where she came to trust one of their researchers, and the other was a cancer self-health programme accessed through its website, magazine and books.

A further narrative informing Fiona's decisions was her concern about losing her fertility due to the chemotherapy. Therefore, after diagnosis, Fiona had in vitro fertilisation (IVF) as soon as she could. This concern of balancing her ongoing need for a cure for her cancer and her concerns for her future fertility were also part of her desire to find a less toxic alternative to chemotherapy. Her exploration of several CAM modalities included attending an 'integrative clinic' and having mistletoe and hypothermia therapy, as well as partaking in art therapy and eurhythmy (a movement-based therapy). Elsewhere, Fiona also tried homeopathy, herbal remedies, theta healing (using theta brain waves to heal), Chris Woollams' Rainbow Diet (Woollams, 2008), kinesiology, installing a home sauna, acupuncture, visualisations and supplements - including reishi mushrooms. Fiona also 
looked into, but largely due to the cost did not take up, intravenous vitamin $\mathrm{C}$, having a thermogram (a form of imaging) and a blood route (a herbal chemotherapy).

However, Fiona's exploration of alternatives proved disappointing: 'I think that up until the end of that year [2008] I was not actually seeing much result in terms of the tumour shrinking'. Despite her pursuit of an alternative treatment to chemotherapy and surgery, Fiona had not completely withdrawn from the National Health Service (NHS) and biomedical care as she had continued to attend her oncology appointments and have radiological scans (Horneber et al., 2012). In this time, Fiona found the first consultant oncologist, who had diagnosed her, to be patronising and defensive in her attitude to Fiona's choices. But after Fiona had returned from the integrative clinic, the cancer selfhealth helpline recommended that she try another NHS hospital. This time she found the consultant to be neutral in his position on her use of complementary therapies, which Fiona found to be helpful. Moreover, this consultant offered Fiona a hormonal chemotherapy that would not affect her fertility in the long term - a treatment Fiona described she was still 'resistant' to, but took up.

Fiona's narrative explored a classic tension between the ideological attraction of complementary and alternative therapies and the questions of efficacy that they posed (Sharma, 1994). For Fiona, this was not just an abstract exercise. She sought to experiment empirically, using her body and cancer as a testing ground. But ultimately, she had to balance her intellectual exploration with her need for physical results. Fiona explained how she went about making the decision to have chemotherapy later on in her account:

... I then spoke to [researcher] $\ldots$ at Cancer Options ... at that point I just said 'what do you think I should do?' He said, 'I think that your best option is to do chemotherapy'. So again I was very resistant. I was referred to another person who does something that's called 'life alignment' but she's a body psychotherapist. ... Again she works with the body to see what the body says. Again, she tested me to see if chemotherapy was now the next step. At that point the muscles she was testing said, 'yes, chemotherapy is the next step and that all that I had done up to then was right'. It was preparation work and I had given myself a real health boost by using all these techniques. After that session I just thought 'okay, that's the decision. I'll go forward and know that it was a decision that I've made'. It wasn't made for me. I hadn't been pushed into this. So I said to the hospital I'll go for it.

Fiona consulted a biomedical researcher, who was sympathetic to complementary therapies, as well as a complementary practitioner. The former provided the evidencebased rationale; the latter assisted Fiona in forming an embodied response that she needed in order to go on to, still reluctantly, chemotherapy. Working with your complementary therapist to listen to yourself and body is an important aspect of using complementary therapies (Gale, 2011; Sointu, 2013; Tarr, 2011). For Fiona, this entailed being aware of her emotional needs and finding ways to balance these as she progressed through her treatment:

For me, its been a journey of trying to keep a kind of balance of, well certainly trying to keep my feet on the ground; one foot in the hospital as well as exploring a lot of other things.

Fiona's narrative followed that of cancer self-health in that she described her attitude not as a rejection of biomedicine, but rather that she believed there was more to health 
than biomedicine could offer (Meurk et al., 2013; Sointu, 2013). Her use of cancer selfhealth was therefore seen to provide hope and be part of a 'pioneering exploration' (to paraphrase her) of new treatments and techniques, balancing the effects of biomedical care - from the impact of chemotherapy to the psychological and emotional effects of biomedical treatment. Similarly, the only idea of balance initially structuring Fiona's narrative was balance as a pre-objectified goal. Fiona sought to find the treatment to cure cancer with minimal long-term effects on her body and fertility. Here, her use of cancer self-health was concerned with taking a wider perspective on things, bringing in factors into decision making and accountability that might otherwise have been marginalised or undervalued (Broom, 2009). In doing so, Fiona sought to objectify a satisfactory compromise that will stand over time.

Although Fiona's story started by seeking an alternative to chemotherapy, because her cancer failed to respond, she then returned to undertake biomedical treatments. However, Fiona did not write her exploration off as wasted time. Instead, 'It was preparation work and [I] had given myself a real health boost by using all these techniques'. Furthermore, the alternative treatments were now there to complement the biomedical, '[The chemotherapy] did have side effects, which I did try and control with homeopathy'. The move from seeking a balanced state of health and wellbeing to one that was part of an ongoing process could be seen in the shift in how her decision to have chemotherapy was expressed. The CAM work, which was at first seen to be the balance (i.e. contra) to biomedicine's treatments, became retrospectively offset as 'preparation' credited to her body over the previous months. In turn, Fiona's narrative shifted from a pursuit of an alternative to chemotherapy, to an ongoing need to complement and mitigate the effects of chemotherapy and cancer in her life. This change in Fiona's experience of cancer selfhealth also had implications for the definition that Fiona was using for efficacy:

... I feel like I have had a huge sea of complementary therapies for the past year and a half. I have always been quite interested, but I feel like I have really explored quite a lot since the diagnosis. And I feel that it has probably worked well for me, because a lot of people say that I don't really look like, you know, so worst for wear as perhaps some people do. I don't know if that is to do with all these complementary therapies or luck of the draw or whatever. But I think, I feel in myself it's probably because I have kept a strong inspiration going. Complementary therapies are anything that works with the health of the body rather than kills off the immune system, is the way to go really. The way that healing should go.

Although no alternative therapy provided Fiona with that elusive shrinking of the tumour and so mainly disappointed her, she was still able to draw from them the idea that they had, actually, complemented biomedical treatments. The complementary treatments she undertook went from ineffectual, as judged by the non-reduction of her tumour, to effective, in that they prepared her body for the chemotherapy as judged by the less severe side effects she experienced. This was no better expressed than when she reflected on how she - in her body - had coped with the effects of the treatments, noting how friends had told her that she did not look like someone who was having chemotherapy.

In turn, this retrospective balancing became a template for future actions as complementary therapies were now 'anything that works with the health of the body rather than kills off the immune system'. It is possible to see an important shift in the temporal and 
spatial forms in operation in Fiona's experience of balance. Here, when balancing was an ongoing process, it incorporated retrospective considerations as well as imagined future trajectories of balancing, which were used in situ to form an ongoing account. That is, it was a modality that made sense of past and forthcoming decisions from her situated and embodied position (Broom, 2009; Meurk et al., 2013; Sointu, 2013).

As noted above, the use of cancer self-health was not restricted to its mitigating effects of chemotherapy on the body. Fiona also found that using a cancer self-health approach provided changes in her experience of having cancer (Meurk, 2013; Sointu, 2013). Fiona's story can be seen as an important reminder that an internalist account of balance need not be an abstracted one. She described how it was important to deal with the emotional issues that diagnosis and treatment of cancer brought. Fiona explained that in her pursuit of an alternative to chemotherapy, she used both a form of visualisation and, separately, theta healing. In both cases, she said she undertook them with gusto, only to become disillusioned as the physical changes failed to materialise. But she also noted how they failed her emotionally. That she found them to be 'flimsy' and full of 'wishful thinking', which could have led her to become 'deluded' She described how people she knew who had used these therapies had made things worse for themselves by ignoring the facts of their cancer. Instead, Fiona sought to fashion a form of realism using the affirmative ethos of cancer self-health, but combined with staying grounded through 'monitoring scientifically what is going on' Thus, Fiona marked out how, on an emotional plane, she must take up an attitude to living that accepted the reality that cancer brought, facing her mortality and the pain of the disease and treatment while not succumbing to purely denial, fatalistic or hyper-positive attitudes:

I think there needs to be a balance of allowing yourself to feel terrible about it all and just feel 'life isn't fair, why should I have this?' Just to feel all the gritty, difficult feelings - I probably would be saying this because I am a psychotherapist ... Just to accept it rather than rise above it, I feel is a much better approach. That's why I was speaking about the flimsiness of just creating your own reality - all retraction etcetera, etcetera.

Fiona's story shows how internalist and process conceptualisations of balance helped her to take an embodied and empirical attitude to testing the treatments and therapies she used. In the above quote, Fiona's use of complementary therapies was now about finding ways to cope with the ongoing demands of chemotherapy. She listened to her body and heard an ongoing narrative of changing emotional needs (Gale, 2011; Meurk, 2013; Sointu, 2013). Fiona spoke of how she had sought not to ignore or 'push under the carpet' 'darker' feelings about her cancer. She shared some of the suspicions that argue selfhealth can lead to denial of the biomedical reality (Youll and Meekosha, 2011), yet she drew on both her previous experiences as well as the cancer self-health literature to find a way to 'accept' her feelings. While acceptance and 'being authentic' are also part of the cancer self-health techniques (Bell, 2010; Sointu, 2011), Fiona's subjectivisation of balance was an attempt at a pragmatic-realism. She hoped to avoid being caught in an abstracted and objectivising ideology or rationality that 'blinds' her to the reality of her situation. 
Fiona was able to do this, at different times, by moving between ideas of her self as either an object or subject within her subjectivity (Foucault, 2005). At times, Fiona's account demonstrated the strong, although diffuse, influence of much of psychotherapeutic thought within both her story and the cancer self-health field generally (Fries, 2008; Fullagar, 2002). However, she also provided recognition of the complex formation of narratives that were involved in her subjectivation. Fiona showed that an open and movable perception of her self was necessary in order to move from balance as a state to an internalist process orientation - a movement that was key to Fiona maintaining her criticality.

\section{Karen - balancing support: rehumanising the embodied self}

Karen's story, like Fiona's, was concerned with how she should balance her anxieties about biomedicine with her experiences as a practitioner of Alexander Technique. For Karen, this was further complicated as it also involved balancing what was right for her as a mother to her young son. However, while seeking the right balance pushed Fiona towards an empirically grounded experimentation with complementary therapies, for Karen, finding the right balance was more about ensuring she had the support she needed to continue both with her biomedical treatments and in her role as a mother. That is, treatments and therapies from CAM and biomedicine were framed as forms of support, and what mattered for Karen was that these were balanced, so that no particular form of support could dominate her self, health or life.

Karen told me that she was diagnosed with breast cancer in February 2009, when she was on holiday in India with her husband and young son. She decided to finish her holiday as she was told that she did not have to rush back, which she said also enabled her to be distracted from what 'it' meant. However, when she returned to the United Kingdom, 'it became much more real and alarming', a fear that was not helped by a long-standing phobia of hospitals. Nonetheless, Karen spoke of how she found the oncology team to be 'lovely, very dedicated, very heart centred', unlike other mainstream health professionals she had encountered until that point. But her warm sentiments did not extend to the environment that they worked in, which she found to be 'quite alien to healing and I felt very sterile hospital environment, very frightening looking machinery, metallic sort of environment'. In order to help her with her decisions, Karen contacted a local breast cancer support group that provided her with information and guidance on breast cancer and cancer self-health approaches.

Unfortunately for Karen, her tumour was found to be quite large and she was advised that her best option was to have chemotherapy before surgery, in order to shrink the tumour and to help reduce the severity of the surgery she would later need. This came as quite a surprise to Karen who had a close friend who had breast cancer and who did not have chemotherapy, so Karen was not expecting to have this treatment. Moreover, Karen explained that she was reluctant to have chemotherapy based on her knowledge of it as a 'body worker' and because she was aware of the advantages of alternative treatments. However, she explained that 'because I have got an 11-year-old son, I felt that statistics of just going alternative were not great. I made the decision, all-be-it against every cell in my body, to agree to the chemotherapy'. 
As an established complementary therapy practitioner, Karen talked easily of being aware of where 'every cell in [her] body' wanted to take her (Gale, 2011; Tarr, 2011). While Karen's first concern was to balance her ideological affinities with empirical results, there was also a second aspect to Karen's reluctance to take a purely alternative route. She later recounted several examples of people who did take an alternative route, but she drew out significant problems with each of these. For example, Karen explained how a particular treatment (Gerson diet) came to overshadow every aspect of a friend's life and the lives of their family and friends. For Karen, the treatment - be it chemotherapy or CAM - could not be allowed to dictate all aspects of her life or the life of her son.

Karen's main concern was with the question of how to balance the forms of familial, emotional and physical support she needed during her illness while also avoiding taking up an extreme position. For example, she highlighted the importance of touch in supporting her move back from the 'alien' and 'sterile' clinical setting of her chemotherapy to life as a wife and mother (Sointu, 2013). This worked on a number of levels:

... I would have chemo on Thursday and I would see her [shiatsu practitioner] the week after. And what it helped me to do was to put me back into my body. Because with the chemo I realised I was sort of, so didn't want to be there, I was spacing out. I felt very, very spaced out I suppose is the word. And having the hands on, having that gentle healing touch just put me back into my body and helped me to breathe again and helped me to relax and let go of a lot of tension. I didn't realise how much tension I was holding really. It helped me on other levels ... The anti-sickness tablets made me very constipated and the shiatsu, every time, just balanced me out. I was able to go to the loo after the treatment. So very tangible benefits just to help with all the drugs I was taking really.

As in Fiona's account, the use of complementary therapies helped in balancing the effects of the biomedical treatment and thus supported Karen through the chemotherapy, returning her to an optimal objectified balanced state (Lipworth et al., 2011):

So it was really the therapies that helped me to cope with the treatment I was having. Without it I think I would have really felt very vulnerable, it just about put me back together again in time for the next dose of chemo. And it just made it easier for me to cope really.

Karen's use of complementary therapies then was about finding ways to cope with the ongoing demands of chemotherapy and of having to attend an 'alien' environment. Having two spaces of care helped one balance the other; while she was in either one, the concern was with optimising (or minimising) a particular state of mind or body, yet the time and movement between the two became a process that allowed her to counter one against the other. At other times, it was possible to hear Karen say that the complementary therapies helped her physically cope, but in others, there was a sense that having an emotional experience of balance was an important part of how she managed what was happening to her.

Karen went on to describe the balance that she wanted to achieve through her use of shiatsu and reiki: 'I think having the therapy work, with the shiatsu particularly was just made me feel human again. Having the chemo was a very dehumanising experience'. 
Rehumanising herself through balancing out the physical and emotional effects of chemotherapy then became an embodied practice (Meurk, 2013; Sointu, 2013). She went on to say,

So to kind of have an antidote to that [chemotherapy ward], the therapy was like going from hell to heaven, because it was gentle, it was focused totally on me and my needs, it was a healing environment, I always came away feeling nurtured and more whole. Whereas, the hospital environment was very fragmenting, very scary, very alien really.

Much of Karen's story was therefore about not letting any one treatment or location dominate her life. Instead, by balancing one against the other, she found that she was able to draw on the benefits of both, without submitting wholly to either. In doing so, Karen's use of balance saw her balancing the physiological effects of her cancer and her oncology treatments with her weekly body therapies, returning her to an objectified optimal state. However, Karen also linked returning her body to a balanced state to balancing her emotional and mental states, that is, taking an internalist approach to conceptualising balance as a state (Lipworth et al., 2011). But Karen's account also showed how this movement continued, in other circumstances, so that balance was also conceptualised as a process that allowed her to manage the forms of support available to her. For example,

I am a bit schizophrenic, I sort of try it and I think 'oh to hell with it - I fancy some cheese!' Because I was, I did go vegan for about five months and I really missed cheese a lot. So I would feel, I would have a little bit, and I would feel really guilty. The nutritionist at the [Centre] said to me, 'look just have the 80 to, 20 sort of rule'. Which is 80 percent of the time eat healthily and, 20 percent of the time, you know have some cheese, have some chocolate, have some alcohol. And don't feel guilty when you do it, because that isn't going to make you, isn't going to help. So I still feel guilty when I have dairy, I have to say, because of having read that Jane Plant book, I think, 'Am I ... Is this a death wish that I am eating this bit of yogurt' ... Which is crazy really. I think my decisions are based more on intui- not intuition, but just sort of gut feeling at the time. As you say, you can read one book and it says one thing and another bit of research says something else - you just go round and round. So I am not particularly consistent.

[Interviewer] Sort of case-by-case?

Yeah sort of week-by-week really ...

Karen described a situation here that was, to her, much less certain than the decision to have chemotherapy. Many might also argue that the stakes were also a lot lower. In contrast to choosing chemotherapy, a potentially life-saving treatment, deciding whether to eat cheese or yogurt does not seem to hold the same sort of consequences. It might be that Karen too would agree that it was a less important decision. Nonetheless, it could be argued that it was a more 'vital' decision for Karen affecting, as it appeared to do, questions of how she saw herself living her life (Foucault, 2005).

Therefore, her dilemma was clearly one that provided some cause for reflection. Karen did not know what was the best thing to do, even when provided with a rule from the Centre's nutritionist. Karen said she had read conflicting accounts of whether dairy 
caused breast cancer or not (such as Jane Plant's (2007) book Your Life in Your Hands). She also spoke of her concern not to do anything to aggravate her health, but it was also clear that she did not want to go to an extreme (Broom and Tovey, 2007). Here, Karen again sought to balance the benefits that altering her diet might bring while avoiding the excesses of a purely alternative lifestyle. However, on this occasion, it was clear that Karen was attempting to integrate and manage several tensions in her decision (Broom, 2009). Her inconsistency denoted an ongoing process whereby past compromises were not necessarily a predictable indicator of what might come next. Karen may have been seeking an optimal state of wellness and wellbeing, but she also recognised that in order to avoid the excesses of any one approach, she needed to move between influences and constantly re-evaluate her position.

\section{Discussion}

In order to better understand the experiences of balance of people with cancer who use cancer self-health, this article considered the obligations that were promoted and, more importantly, how these were found by the user to inculcate them to undertake particular acts. Part of this is the recognition of the continuum that the self subjects itself within and then the attempts to move beyond (see Foucault, 1998, 2005). What reference to this body of Foucault's work allowed was recognition that narratives of balance from CAM and biomedicine were not simply about subjecting the self to an objectifying discourse. Moreover, when conceptualising the subject as bricoleur (Broom, 2009), we recognise within that is an (always) incomplete subjectivity, leaving any process of subjectification as partial. In Fiona's and Karen's stories, we frequently saw a subjectivation of balance that involved the self seeking an ongoing placing of one's self as a subject of possible acts in one's subjectivity. These subjectivised narratives and experiences of balance therefore have an ontological dimension related to producing the subject as a certain kind of relationship between the individual and her self (see McGushin, 2007). At those times, balance in cancer self-health use was therefore better seen as an exercise that adds something to a delineated, yet incomplete self (Meurk et al., 2013).

In order to explore how balance might be inculcated and affect peoples' experiences of illness, this analysis made the distinction between the discursive and conceptual equipment of balance that Fiona and Karen used (via Lipworth et al., 2011) and the mode of subjectivation through which these are made sense of (Foucault, 2005; McGushin, 2007). What this enabled was an exploration of a process of transformation, as the grand narratives move from an authority of the reasoned word into a truth that is to be lived. What Lipworth et al.'s (2011) typology provided was a focus on those moments where narratives of balance were inculcated as a pre-determined state, as well as the processes where subjectivations of balance involved exercises to assess the emotional and ethical implications for Fiona's or Karen's self, health and life (Frank, 1998; Sayer, 2011). In the latter, these narratives moved from memory, habit or discursive form (e.g. narrative) to become active in Fiona's and Karen's corporeality, a thinking-body, and not just a biological process (McGushin, 2007; Meurk et al., 2013; Sointu, 2013).

The subjectivation of balance narratives could therefore add something to the self, which transformed the individual from an object into a subject. That is, the equipment 
that cancer self-health provided, the 'companion stories' (Frank, 2010: 43) that can be used to protect the individual from the dangers they may confront in life, were discursive in nature (McGushin, 2007). However, Fiona and Karen described that, as well as discursive changes in their lives, cancer self-health approaches helped them change both how life feels and how life is experienced. In doing so, any understanding of their selves as objects of normativity became slippery, thus allowing Fiona and Karen to claim their criticality. In particular, Fiona and Karen showed that it was the trajectory of the movement in their balancing exercises between experiences of balance - internalist or externalist, state or process - that allowed them to maintain a claim to their independence of thought (Broom, 2009; Lipworth et al., 2011; Meurk et al., 2013).

Narratives of balance are part of wider norms of individualised responsibility found in healthcare, which involves disciplinary discourses, practices and techniques that seek to impose ways that people should care for themselves (Broom and Tovey, 2007; Novas and Rose, 2000). Yet, the discursive equipment that cancer self-health provided could not solely be understood as a technology of self-governance (e.g. Fries, 2008; Fullagar, 2002; Illouz, 2008; Stacey, 1997). Rather, the wider argument here is that it is important to consider not only how such normative frameworks are taken up (see Broom, 2009), but the ethical and emotional trajectories within which they are enacted (see Frank, 1998; Sayer, 2011). That is, Fiona's and Karen's stories showed how experiences of balance were a way to situate their selves, while recognising and accepting the system of rationality used to posit their selves as an object in that particular point in the world (Foucault, 2005). As such, it was possible to show how and when narratives of balance constituted a form of (unthinking) routinised normalisation, an adherence to a grand narrative, and how it was possible to form a critical self in the exercises of subjectivation.

\section{Acknowledgements}

I would like to thank the reviewers for their helpful and insightful comments. I would also like to thank Alex Broom and Emma Kirby (University of New South Wales) for their comments on an earlier version of this article. Finally, I am especially grateful to my supervisor, Nikolas Rose (King's College, London), and $\mathrm{PhD}$ examiners, Lisa Blackman (Goldsmiths University) and Arthur Frank (University of Calgary), for their comments on the chapter in my doctorate thesis from which this article draws.

\section{Declaration of Conflicting Interests}

The author(s) declared no potential conflicts of interest with respect to the research, authorship, and/or publication of this article.

\section{Funding}

The author(s) received no financial support for the research, authorship, and/or publication of this article.

\section{Note}

1. This article is located within a body of work inspired by Foucault's (2005) lectures at the College de France (1982-1984). 


\section{References}

Armstrong N and Murphy E (2012) Conceptualizing resistance. Health 16: 314-326.

Back L (2007) The Art of Listening. Oxford: Berg.

Beales D (2003) Science and the Bristol approach. In: Cooke HJ (ed.) The Bristol Approach to Living with Cancer. London: Robinson Publishing, pp. 23-59.

Bell K (2010) Cancer survivorship, mor(t)ality and lifestyle discourses on cancer prevention. Sociology Health and Illness 32: 349-364.

Bendelow G (2009) Health, Emotion and the Body. Cambridge: Polity Press.

Bivins R (2007) Alternative Medicine? A History. Oxford: OUP Oxford.

Broom A (2009) Intuition, subjectivity, and Le bricoleur: Cancer patients' accounts of negotiating a plurality of therapeutic options. Qualitative Health Research 19: 1050-1059.

Broom A and Tovey P (2007) The dialectical tension between individuation and depersonalization in cancer patients' mediation of complementary, alternative and biomedical cancer treatments. Sociology 41: 1021-1039.

Cant S and Sharma U (1998) A New Medical Pluralism: Complementary Medicine, Doctors, Patients And The State. London: Routledge.

Christiansen CH and Matuska KM (2006) Lifestyle balance: A review of concepts and research. Journal of Occupational Science 13: 49-61.

Coulter ID (2004) Integration and paradigm clash: The practical difficulties of integrative medicine. In: Tovey P, Easthope G and Adams J (eds) The Mainstreaming of Complementary and Alternative Medicine: Studies in Social Context. London: Routledge, pp. 103-122.

Daykin N, McClean S and Bunt L (2007) Creativity, identity and healing: Participants' accounts of music therapy in cancer care. Health 11(3): 349-370.

Farmer P (1996) On suffering and structural violence: A view from below. Daedalus 125: 261-283.

Flesch H (2010) Balancing act: Women and the study of complementary and alternative medicine. Complementary Therapies in Clinical Practice 16: 20-25.

Flyvbjerg B (2006) Five misunderstandings about case-study research. Qualitative Inquiry 12(2): 219-245.

Foucault M (1998) The History of Sexuality, 2: The Use of Pleasure. London: Penguin.

Foucault M (2005) The Hermeneutics of the Subject: Lectures at the College de France 19811982. New York: Palgrave Macmillan.

Frank AW (1995) The Wounded Storyteller: Body, Illness and Ethics. London: The University of Chicago Press.

Frank AW (1998) Stories of illness as care of the self: A Foucauldian dialogue. Health 2(3): 329-348.

Frank AW (2010) Letting Stories Breathe: A Socio-Narratology. London: Chicago University Press.

Fries CJ (2008) Governing the health of the hybrid self: Integrative medicine, neoliberalism, and the shifting biopolitics of subjectivity. Health Sociology Review 17: 353-367.

Fullagar S (2002) Governing the healthy body: Discourses of leisure and lifestyle within Australian Health Policy. Health 6(1): 69-84.

Gale NK (2011) From body-talk to body-stories: Body work in complementary and alternative medicine. Sociology of Health and Illness 33: 237-251.

Gale NK (2014) The sociology of traditional, complementary and alternative medicine. Sociology Compass 8(6): 805-822.

Goldacre B (2008) Bad Science. London: Fourth Estate.

Harrer S (2005) The theme of subjectivity in Foucault's lecture series L'Herméneutique du Sujet. Foucault Studies 2: 75-96. 
Horneber M, Bueschel G, Dennert G, et al. (2012) How many cancer patients use complementary and alternative medicine: A systematic review and metaanalysis. Integrative Cancer Therapies 11(3): 187-203.

Illouz E (2008) Saving the Modern Soul: Therapy, emotions and the Culture of the Self-Help. London: University of California Press.

Lawton J (1998) Contemporary hospice care: The sequestration of the unbounded body and 'dirty dying'. Sociology of Health and Illness 20: 121-143.

Lipworth WL, Hooker C and Carter SM (2011) Balance, balancing, and health. Qualitative Health Research 21: 714-725.

Lorenz LS (2011) A way into empathy: A 'case' of photo-elicitation in illness research. Health 15(3): 259-275.

MacArtney JI (2015) Cancer self-health programmes: An ethos for negotiating multiplicities of healthcare. Health Sociology Review. Epub ahead of print 9 October. DOI: 10.1080/14461242.2015.1082436.

MacArtney JI and Wahlberg A (2014) The problem of complementary and alternative medicine use today: Eyes half closed? Qualitative Health Research 24: 114-123. DOI: 10.1177/ 1049732313518977.

McGushin EF (2007) Foucault's Askēsis: An Introduction to the Philosophical Life. Evanston, IL: Northwestern University Press.

Meurk C, Broom A, Adams J, et al. (2013) Bodies of knowledge: Nature, holism and women's plural health practices. Health 17(3): 300-318.

Mullen K (1992) A question of balance: Health behaviour and work context among male Glaswegians. Sociology of Health and Illness 14: 73-97.

Nissen N (2013) Women's bodies and women's lives in western herbal medicine in the UK. Medical Anthropology 32: 75-91.

Novas C and Rose N (2000) Genetic risk and the birth of the somatic individual. Economy and Society 29: 485-513.

Overcash JA (2003) Narrative research: A review of methodology and relevance to clinical practice. Critical Reviews in Oncology/Hematology 48: 179-184.

Patwardhan B, Warude D, Pushpangadan P, et al. (2005) Ayurveda and traditional Chinese medicine: A comparative overview. Evidence Based Complementary and Alternative Medicine 2: 465-473.

Plant JA (2007) Your Life in Your Hands: Understand, Prevent and Overcome Breast Cancer and Ovarian Cancer. London: Virgin Books.

Riessman CK (2003) Performing identities in illness narrative: Masculinity and multiple sclerosis. Qualitative Research 3: 5-33.

Rose N (2007) The Politics of Life Itself: Biomedicine, Power, and Subjectivity in the Twenty-First Century. Oxford: Princeton University Press.

Saks M (2003) Bringing together the orthodox and alternative in health care. Complementary Therapies in Medicine 11: 142-145.

Sayer A (2011) Why Things Matter to People: Social Science, Values and the Ethical Life. Cambridge: Cambridge University Press.

Shapin S (2011) The Long History of Dietetics: Thinking Sociologically about Food, Knowledge and the Self(LSE Public Lecture Series). London: London School of Economics. Available at: http://www.youtube.com/watch?v=GTRbdEFjhOk

Sharma U (1994) The Equation of Responsibility: Complementary practitioners and their Patients (ed S Budd and U Sharma). London: Routledge.

Singh S and Ernst E (2009) Trick or Treatment? Alternative Medicine on Trial. London: Corgi.

Sointu E (2006a) Recognition and the Creation of Wellbeing. Sociology 40: 493-510. 
Sointu E (2006b) The search for wellbeing in alternative and complementary health practices. Sociology of Health and Illness 28: 330-349.

Sointu E (2011) Detraditionalisation, gender and alternative and complementary medicines. Sociology of Health and Illness 33: 356-371.

Sointu E (2012) Theorizing Complementary and Alternative Medicines: Wellbeing, Self, Gender, Class. London: Palgrave Macmillan.

Sointu E (2013) Complementary and alternative medicines, embodied subjectivity and experiences of healing. Health 17(5): 530-545.

Sparkes AC, Perez-Samaniego V and Smith B (2012) Social comparison processes, narrative mapping and their shaping of the cancer experience: A case study of an elite athlete. Health 16(5): 467-488.

Stacey J (1997) Teratologies: A Cultural Study of Cancer. London: Routledge.

Tarr J (2011) Educating with the hands: Working on the body/self in Alexander Technique. Sociology of Health and Illness 33(2): 252-265.

Wagman P, Bjorklund A, Hakansson C, et al. (2011) Perceptions of life balance among a working population in Sweden. Qualitative Health Research 21: 410-418.

Woollams C (2008) The Rainbow Diet. London: Health Issues Ltd.

Wahlberg A (2007) A quackery with a difference: New medical pluralism and the problem of 'dangerous practitioners' in the United Kingdom. Social Science and Medicine 65(11): 2307-2316.

Yin RK (2003) Case Study Research: Design and Methods. Thousand Oaks, CA: SAGE.

Youll J and Meekosha H (2011) Always look on the bright side of life: Cancer and positive thinking. Journal of Sociology 49: 22-40.

\section{Author biography}

John I. MacArtney is a qualitative researcher at the Health Experiences Research Group, Nuffield Department of Primary Care Health Sciences, at the University of Oxford. 